\title{
Characterization of cluster of differentiation 47 expression and its potential as a therapeutic target in esophageal squamous cell cancer
}

\author{
CHUN-LIN ZHAO ${ }^{1}$, SHUANG YU ${ }^{2}$, SHU-HUI WANG ${ }^{2}$, SHI-GANG LI $^{2}$, ZHI-JU WANG ${ }^{3 *}$ and SHENG-NA HAN ${ }^{2 *}$ \\ ${ }^{1}$ Department of General Surgery, The First Affiliated Hospital of Zhengzhou University, Zhengzhou, \\ Henan 450052; Departments of ${ }^{2}$ Pharmacology and ${ }^{3}$ Physiology, School of Basic Medical Sciences, \\ Zhengzhou University, Zhengzhou, Henan 450001, P.R. China
}

Received June 26, 2017; Accepted October 13, 2017

DOI: $10.3892 / \mathrm{ol} .2017 .7447$

\begin{abstract}
The increased expression of cluster of differentiation (CD)47 has been identified in a number of different tumor types and is recognized as an adverse prognostic factor that indicates an increased risk of mortality in patients. The binding of CD47 to signal regulatory protein $\alpha(\operatorname{SIRP} \alpha)$ inhibits the macrophage phagocytosis of tumor cells by triggering an inhibitory 'do not eat me' signal. This is one of the mechanisms used by tumor cells to evade immune surveillance. In the present study, CD47 levels and macrophage infiltration were assessed in patients with esophageal squamous cell cancer (ESCC). CD47-overexpressing ESCC cell lines were selected and human M2 macrophage phagocytic activity was measured. The results revealed that CD47 is highly expressed and macrophages are markedly infiltrated in cancerous tissue compared with non-cancerous tissue. High CD47 expression was detected in ESCC cell lines and the results of a phagocytosis assay indicated that human M2 macrophages phagocytized tumor cells in a dose-dependent manner following the blocking of CD47-SIRP $\alpha$ signaling by anti-CD47 antibodies. The results of the present study therefore support the use of anti-CD47 immunotherapy to treat patients with ESCC.
\end{abstract}

Correspondence to: Dr Sheng-Na Han, Department of Pharmacology, School of Basic Medical Sciences, Zhengzhou University, 100 Science Avenue, Zhengzhou, Henan 450001, P.R. China

E-mail: hsn@zzu.edu.cn

Dr Zhi-Ju Wang, Department of Physiology, School of Basic Medical Sciences, Zhengzhou University, 100 Science Avenue, Zhengzhou, Henan 450001, P.R. China

E-mail: zhijuwang@zzu.edu.cn

${ }^{*}$ Contributed equally

Key words: esophageal cancer, cluster of differentiation 47, signal regulatory protein $\alpha$, macrophages

\section{Introduction}

Esophageal cancer (EC) is a common cause of cancerassociated mortality worldwide (1). In total, $\sim 0.5$ million individuals are diagnosed with EC every year in China (2). There are two major histological subtypes of EC: Esophageal squamous cell cancer (ESCC), which is the most common type worldwide, including in China, and esophageal adenocarcinoma (EAC), which is the fastest increasing subtype of EC being diagnosed in Western countries $(3,4)$. Currently, the standard treatment of EC is surgery combined with chemotherapy and/or radiation, depending on the stage at which the cancer is diagnosed (5). However, the 5-year survival rate of patients with advanced forms of EC remains poor $(5-30 \%)(6,7)$.

The effectiveness of immunotherapy has been clinically proven and may therefore be developed as a novel method of treating cancer (8-10). Treatments that block checkpoint inhibitors, including cytotoxic T-lymphocyte associated protein 4 (CTLA-4), programmed cell death protein (PD-1) and programmed death-ligand 1 (PD-L1), have been approved by the US Food and Drug Administration to treat melanoma, non-small-cell lung cancer, head and neck cancer, renal cancer and non-Hodgkin's lymphoma (8). Compared with standard therapies, remarkable efficacy has been achieved following the use of checkpoint inhibitors; however, a number of patients with melanoma exhibit no response or resistance to immune checkpoint blockades (11-13). Therefore, it is necessary to identify novel targets and strategies to improve current therapies for cancer.

Among the potential novel targets that have been identified, cluster of differentiation (CD) 47 is of particular interest. CD47 is a widely expressed transmembrane protein belonging to the immunoglobulin superfamily (14). The binding of CD47 to signal regulatory protein $\alpha(\operatorname{SIRP} \alpha)$, which is expressed on myeloid cells, induces an inhibitory 'do not eat me' signal that attenuates macrophage phagocytic activity (15). CD47 is highly expressed in many different types of cancer, including breast, ovarian, colon and bladder cancer, glioblastoma and various hematological types of cancer (16-22). Furthermore, high CD47 expression in tumor cells is associated with poor clinical outcomes $(20,22,23)$. It has been suggested that tumors 
evade macrophage phagocytosis by activating the inhibitory signal via the ligation of SIRP $\alpha$ expressed on phagocytes with CD47 (which is highly expressed on cancer cells) (24). Tumors utilize this mechanism to escape immune surveillance.

In the present study, CD47 expression and macrophage infiltration were determined in patients with ESCC. It was assessed whether blocking CD47 signaling with anti-CD47 antibodies enhances macrophage phagocytosis of human ESCC cells in vitro. To the best of our knowledge, the present study is the first to characterize the phagocytic activity of human macrophages against ESCC cells. These results provide rationale and support for the use of anti-CD47 immunotherapy to treat patients with ESCC.

\section{Materials and methods}

Patient samples. ESCC biopsies were collected from 14 patients ( 6 male and 8 female; mean age, $62.7 \pm 7.3$ years old), who underwent potential curative surgery at the First Affiliated Hospital of Zhengzhou University (Zhengzhou, China) between July 2015 and June 2016 (Table I). All tissue samples were collected prior to chemotherapy or radiotherapy. The present study was approved by the Ethics Committee of the First Affiliated Hospital of Zhengzhou University and written informed consent was obtained from each patient. Surgeries were classified as curative as there was no evidence of residual tumors and resected margins were microscopically free of tumors following surgery (R0) (25). Non-cancerous (normal) tissues obtained from ESCC were obtained from the Department of Thoracic Surgery, the First Affiliated Hospital of Zhengzhou University (Henan, China). Samples were divided and either immediately frozen in liquid nitrogen and stored at $-80^{\circ} \mathrm{C}$ for RNA isolation or fixed in $10 \%$ neutral-buffered formalin for $24 \mathrm{~h}\left(22-25^{\circ} \mathrm{C}\right)$ prior to immunohistochemical (IHC) analysis.

Reverse transcription-quantitative polymerase chain reaction $(R T-q P C R)$. Total RNA was isolated from ESCC tissue using TRIzol reagent (cat. no. 15596026; Invitrogen; Thermo Fisher Scientific, Inc., Waltham, MA, USA) and reverse transcribed following the manufacturer's protocol (cat. no. RR047A; Takara Biotechnology Co., Ltd., Dalian, China). Subsequently, qPCR was performed using the SYBR-Green Master mix (cat. no. 4472908; Thermo Fisher Scientific, Inc.) on the 7500 Fast Real-Time PCR system (Applied Biosystems; Thermo Fisher Scientific, Inc.). Thermocycling conditions were as follows; holding on at $50^{\circ} \mathrm{C}$ for $2 \mathrm{~min}$; pre-denaturation at $95^{\circ} \mathrm{C}$ for $2 \mathrm{~min}$; followed by $15 \mathrm{sec}$ at $95^{\circ} \mathrm{C}$ then $1 \mathrm{~min}$ at $60^{\circ} \mathrm{C}$ for 40 cycles; melt curve was at $95^{\circ} \mathrm{C}$ for $15 \mathrm{sec}, 1 \mathrm{~min}$ at $60^{\circ} \mathrm{C}, 15 \mathrm{sec}$ at $95^{\circ} \mathrm{C}$ and $15 \mathrm{sec}$ at $60^{\circ} \mathrm{C}$. The following primers were used: Human CD47 forward, 5'-GGCAATGACGAAGGAGGTTA-3' and reverse, 5'-ATCCGGTGGTATGGATGAGA-3'; and human $\beta$-actin forward, 5'-GGGAAATCGTGCGTGACATT-3' and reverse, 5'-GGAAGGAAGGCTGGAAGAGT-3'. RNA levels were normalized to $\beta$-actin expression and relative expression was calculated using the change-in-quantification $\left(2^{-\Delta \Delta C q}\right)$ method (26).

IHC analysis. IHC analysis was performed to evaluate the expression of CD47 and CD68 in tumor tissues. Specimens were fixed in $10 \%$ neutral-buffered formalin for $24 \mathrm{~h}\left(22-25^{\circ} \mathrm{C}\right)$, embedded in paraffin and cut into $4-\mu$ m-thick sections. Sections were deparaffinized with xylene and rehydrated in a descending series of ethanol. Non-specific staining was blocked by incubating slides with a $5 \%$ bovine serum albumin buffer (cat. no. A8020; Beijing Solarbio Science \& Technology Co., Ltd., Beijing, China) for $30 \mathrm{~min}$ at room temperature. Tissue sections were subsequently incubated with primary antibodies against human CD47 (1:100; cat. no. ab134484; Abcam, Cambridge, MA, USA) and human CD68 (1:100; cat. no. ab955; Abcam) at $4^{\circ} \mathrm{C}$ overnight. CD68 is a glycoprotein that binds to low-density lipoprotein and is expressed on monocytes and macrophages. It is a well-known cell surface marker for macrophages (27). Slides were then incubated for $1 \mathrm{~h}$ at room temperature with horseradish peroxidase-conjugated goat anti-mouse $\operatorname{IgG}(1: 5,000$; cat. no. SA00001-1; Wuhan Sanying Biotechnology, Wuhan, China). Chromagens were detected using 3,3'-diaminobenzidine.

Alternatively, certain sections were stained with hematoxylin and eosin (H\&E) in the absence of primary antibodies separately. Slides were dehydrated and mounted for observation using a light microscope (magnification, x200 and x400).

ESCC cell lines. Human ESCC cell lines TE1, KYSE-30, TE-8, KYSE-270 and TE-10 were purchased from the Shanghai Institute of Biochemistry and Cell Biology (Shanghai, China). Cells were maintained in Roswell Park Memorial Institute 1640 medium (cat. no. 11875; Gibco; Thermo Fisher Scientific, Inc.) supplemented with $10 \%$ fetal bovine serum (cat. no. 10082147; Gibco; Thermo Fisher Scientific, Inc.), $100 \mathrm{U} / \mathrm{ml}$ penicillin and $100 \mu \mathrm{g} / \mathrm{ml}$ streptomycin and cultured in a humidified $5 \% \mathrm{CO}_{2}$ incubator at $37^{\circ} \mathrm{C}$.

Flow cytometry. Flow cytometry was performed to measure the number of different cell types and protein expression in ESCC cell lines. Cells were washed with cold PBS and incubated with fluorescein isothiocyanate (FITC)-conjugated mouse anti-human CD47 primary antibodies as part of the mouse anti-human CD47-FITC detection kit (1:100; cat. no. 11-0479-42; eBioscience; Thermo Fisher Scientific, Inc.) or a corresponding FITC-conjugated mouse immunoglobulin (Ig) G1k isotype control as part of the mouse IgG1k-FITC isotype control detection kit (1:100; cat no. 14-4714-82; eBioscience; Thermo Fisher Scientific, Inc.) for $15 \mathrm{~min}$ at room temperature $\left(22-25^{\circ} \mathrm{C}\right)$. Following washing with PBS, cells were analyzed using a LSRII flow cytometer (BD Biosciences, Franklin Lakes, NJ, USA). Data were analyzed using FlowJo ${ }^{\circledR}$ software (version 10; FlowJo LLC, Ashland, OR, USA).

In vitro phagocytosis assay. ESCC cells were $\mathrm{pHrodo}^{\mathrm{TM}}$ Red-labeled (cat. no. P36600; Molecular Probes; Thermo Fisher Scientific, Inc.) and incubated with human M2 macrophages at $22-25^{\circ} \mathrm{C}$ (in a 2:1 target:effector cell ratio) according to the manufacturer's protocol in the presence of $20 \mu \mathrm{g} / \mathrm{ml}$ mouse IgG1 isotype (control; 1:100; cat. no. BE0083; BioXcell, West Lebanon, NH, USA) or mouse anti-human CD47 antibodies (1:100; cat. no. BE0019-1; BioXcell) for $2 \mathrm{~h}$. Cells were subsequently analyzed using immunofluorescence microscopy (magnification, x100 and x400) to determine the phagocytic index (number of tumor cells ingested/100 macrophages by 
counting). In the dose-response study, the anti-hCD47 antibody concentration was serially diluted from 300 to $0.03 \mu \mathrm{g} / \mathrm{ml}$ by a dilution factor of 3 .

Statistical analysis. Data are presented as the mean \pm standard error of the mean. All data were analyzed using SPSS (version 13; SPSS, Inc., Chicago, IL, USA). One-way analysis of variance was used to detect differences among groups. If a significant difference was identified, the Fisher least significant difference test was used to detect specific differences between the study groups. All experiments were repeated $\geq 3$ times. $\mathrm{P}<0.05$ was considered to indicate a statistically significant difference.

\section{Results}

Patients with ESCC express high levels of CD47. Cancerous tissue and corresponding non-cancerous tissue biopsies were collected from 14 patients with ESCC and CD47 mRNA expression was measured. The results revealed that CD47 mRNA expression was significantly higher in cancerous tissue compared with non-cancerous tissue (Fig. 1A). IHC analysis revealed extensive anti-CD47 staining on the surface of tumor cells, supporting the results of RT-qPCR (Fig. 1B). Additionally, high anti-CD47 staining was observed on the surface of stromal and infiltrated cells, including the presence of fibroblasts and macrophages in the tumor region. In contrast, minimal anti-CD47 staining was observed in the corresponding non-cancerous tissue.

Macrophages are highly infiltrated in patients with ESCC. High expression of surface CD47 helps tumor cells evade immune surveillance by binding to SIRP $\alpha$ expressed on the cell surface of phagocytes (24). To evaluate the status of macrophage infiltration in patients with ESCC, anti-CD68 IHC staining was conducted in cancerous and corresponding non-cancerous tissue. Anti-CD68 staining was detected in the tumor tissue in the infiltrated macrophages and in the extracellular matrix of tumor cells (Fig. 2A). Contrastingly, minimal anti-CD68 staining was observed in the non-cancerous tissue. H\&E staining determined whether immune cell infiltration had occurred. Heavy immune cell infiltration was observed in the cancerous tissue but not in the non-cancerous tissue (Fig. 2B).

CD47 expression was identified in certain cell lines derived from patients with ESCC. Increased CD47 expression has been reported in various tumor cell lines (28). To evaluate whether CD47 is also highly expressed in ESCC, CD47 expression in 5 different ESCC lines were examined using flow cytometry. The results revealed that the TE- 8 cell line expressed high levels of CD47 whereas the KYSE-30 and KYSE-270 cell lines expressed limited amounts of CD47 (Fig. 3A). Levels of CD47 in the TE- 1 and TE-10 cell lines were undetectable (data not shown). The expression of CD47 mRNA in ESCC-derived cell lines was also investigated. The results were consistent with those for RNA expression; it was demonstrated that the TE-8 cell line expressed the highest level of CD47 mRNA (Fig. 3B). KYSE-30 expressed significantly lower mRNA levels compared with TE-8 and KYSE-270 expressed significantly lower levels of CD47 compared with TE-8 and KYSE-30. 

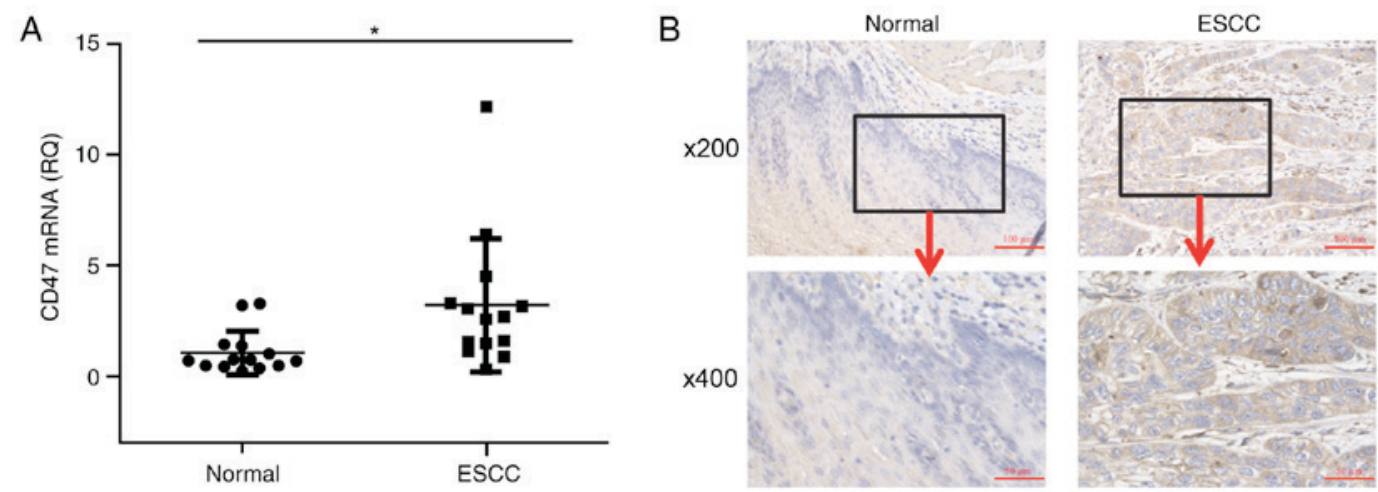

Figure 1. CD47 expression in patients with ESCC. (A) Reverse transcription-quantitative polymerase chain reaction was used to measure the CD47 mRNA expression in cancerous and non-cancerous tissues collected from patients with ESCC ( $\mathrm{n}=14)$. The horizontal lines indicate the mean value. (B) Representative images of immunohistochemistry staining of ESCC tissue with anti-CD47 antibodies (brown). Representative case of CD47-positive (right) and -negative (left) tissue. ${ }^{*} \mathrm{P}<0.05$. CD, cluster of differentiation; ESCC, esophageal squamous cell cancer; RQ, relative quantity.

A

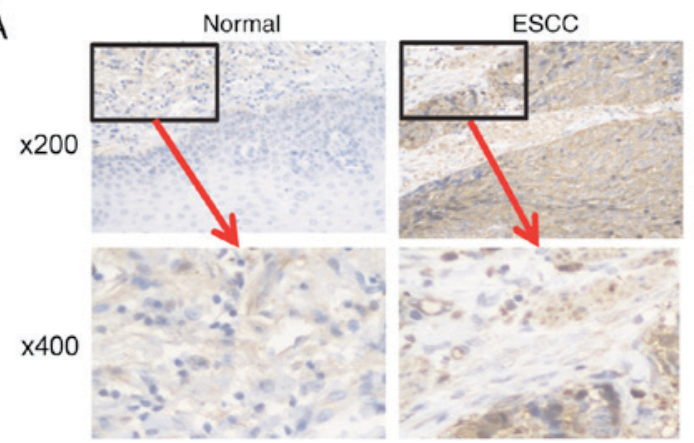

B

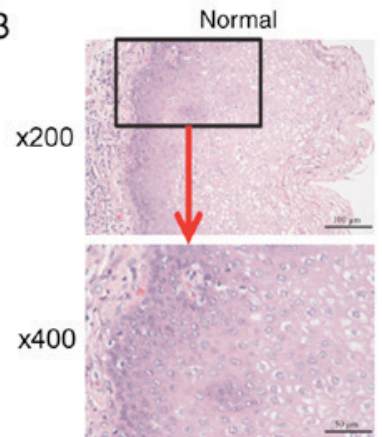

ESCC

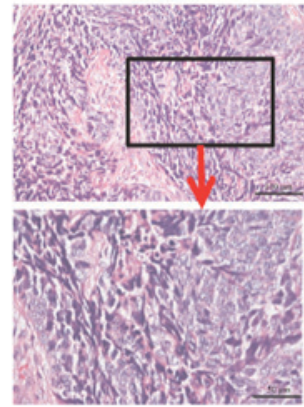

Figure 2. Macrophages are highly infiltrated in patients with ESCC. (A) Immunohistochemical staining for ESCC and normal tissues using the macrophage marker anti-CD68. Representative images of CD68-high (right) and -low (left) tissues. (B) Hematoxylin and eosin staining of ESCC and normal tissues. ESCC, esophageal squamous cell cancer; $\mathrm{CD}$, cluster of differentiation.
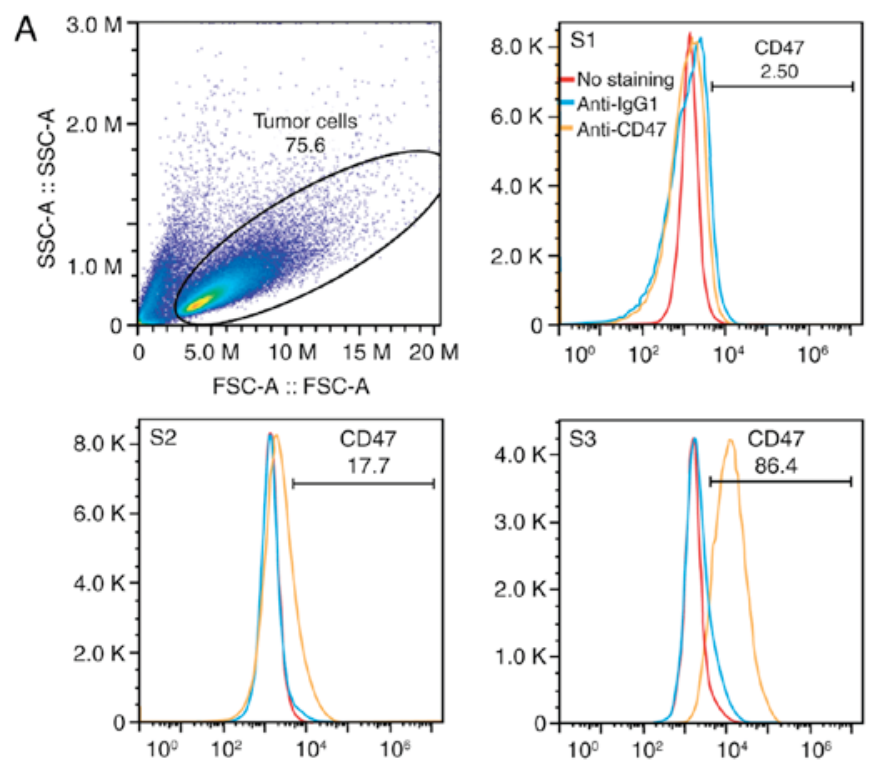

B

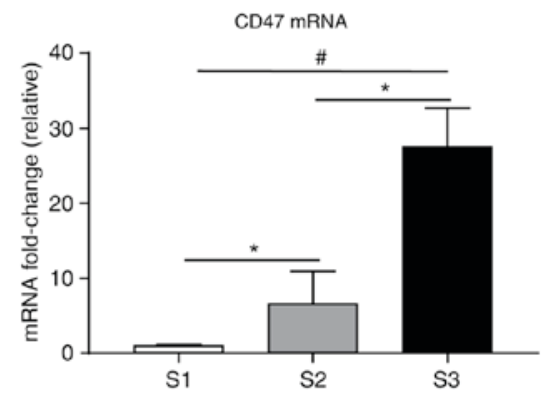

Figure 3. CD47 expression in cell lines derived from patients with esophageal squamous cell cancer. (A) CD47 expression was evaluated by flow cytometry in S1, S2 and S3 cancer cells. (B) CD47 mRNA levels were evaluated by reverse transcription-quantitative polymerase chain reaction in S1, S2 and S3 cancer cells. "P<0.05 and ${ }^{\#} \mathrm{P}<0.01$. S1, KYSE-270; S2, KYSE-30; S3, TE-8; CD, cluster of differentiation; Ig, immunoglobulin; SSC-A, side scatter-A; FSC-A, forward scatter-A.

Human M2 macrophages phagocytize ESCC cells. To determine whether blocking CD47-SIRP $\alpha$ signaling with
anti-CD47 antibodies would activate the 'eat me' signal, a human M2 macrophage phagocytosis assay was performed on 

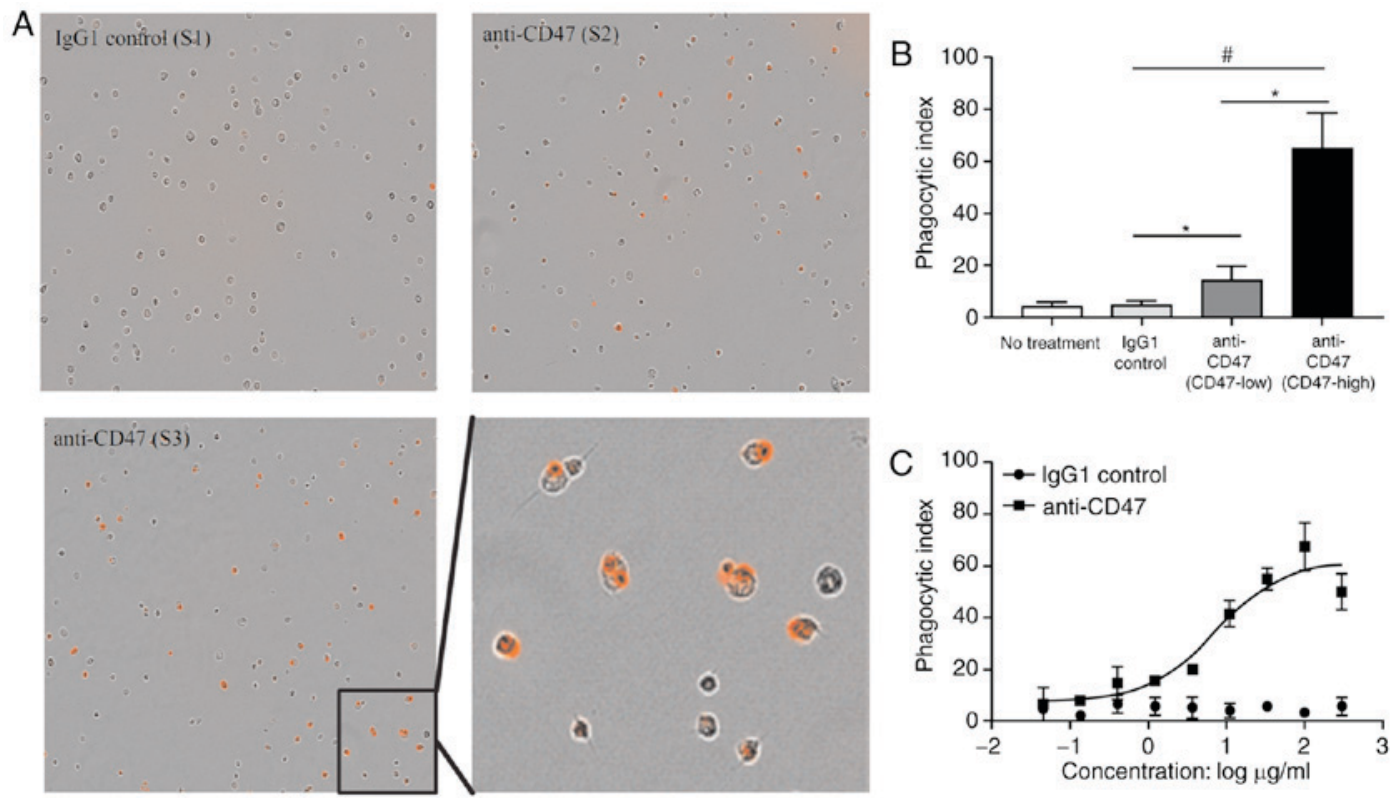

Figure 4. Human macrophages phagocytize esophageal squamous cancer cells. (A) pHrodo Red-labeled esophageal cancer cells were incubated with human M2 macrophages and the indicated antibodies and examined by immunofluorescence microscopy to detect phagocytosis. Photomicrographs from the representative samples are presented (magnification, x200 and x400). (B) Phagocytic activity was assessed by determining the phagocytic index following incubation with the indicated antibodies. (C) Phagocytic activity was assessed by determining the phagocytic index following incubation with dose-titrated indicated antibodies. ${ }^{*} \mathrm{P}<0.05$ and ${ }^{\#} \mathrm{P}<0.01$.

human ESCC cells (KYSE-270, KYSE-30, and TE-8; Fig. 4A). Anti-CD47 $(20 \mu \mathrm{g} / \mathrm{ml})$ treatment significantly increased the M2 macrophage ingestion of TE- 8 cancer cells exhibiting high CD47 expression, compared with KYSE-30 cancer cells exhibiting lower CD47 expression and the IgG1 control group (Fig. 4B). The IgG1 control treatment group exhibited minimal macrophage phagocytic activity and was significantly reduced compared with the TE-8 and KYSE-30 groups. It was also observed that anti-CD47 blocking promoted macrophage phagocytosis of TE- 8 cancer cells in a dose-dependent manner (Fig. 4C).

\section{Discussion}

Out of all the solid tumors, the mortality rate of patients with ESCC is particularly high due to its aggressive dissemination and the absence of clear clinical symptoms $(1,29)$. Although multidisciplinary approaches, including surgery, radiotherapy and chemotherapy have markedly improved patient outcomes, novel therapeutic strategies are required to treat patients with ESCC due to poor survival rates (5).

Checkpoint inhibitor immunotherapy has been evaluated for the treatment of ESCC $(9,10)$. Doi et al (9) demonstrated that pembrolizumab (anti-hPD-1 antibody) treatment in patients with PD-L1-positive ESCC led to a partial response (PR) rate of $29.4 \%$; however no patients exhibited a complete response (CR). Kudo et al (10) also reported that treatment with nivolumab (another anti-hPD-1 antibody) in patients with advanced ESCC and not preselected by PD-L1 status resulted in a PR rate of $15.6 \%$ and a CR rate of $1.6 \%$, with a median overall survival (OS) time of 12.1 months. The results of these studies indicate that anti-PD-1 antibody therapy is a potential treatment for patients with ESCC but suggest that anti-PD-1 alone is not enough to promote tumor regression in the majority of patients with cancer. To produce a robust therapeutic immune response, a combination of treatments may be required.

CD47 is recognized as a checkpoint for the innate immune response and delivers an inhibitory signal when it binds with SIRP $\alpha$ expressed on phagocytes (30-32). Anti-CD47 treatment enhances the efficacy of anti-PD-1 and anti-CTLA-4 in pre-clinical models of ESCC (33). CD47 expression has been used as a novel prognostic marker in patients with ESCC (34) and a study by Yang et al (35) demonstrated that CD47 is a potential target in the treatment of laryngeal squamous cell carcinoma (LSCC). In the present study, patients did not take any anti-cancer medication and samples were collected prior to chemo- or radiotherapy, therefore, the expression of CD47 was unaffected. It has been demonstrated that cancerous tissues expressed significantly higher CD47 levels than non-cancerous tissues in patients with ESCC. IHC staining confirmed that CD47 was highly expressed in the tumor cells of patients with ESCC. These results are consistent with previously published data in which CD47 levels in tumor tissues were significantly higher than those in non-tumor tissues in patients with ESCC or LSCC $(34,35)$. In addition, increased levels of tumor tissue infiltration by macrophages were observed in the current study. Macrophages are one of the major cell types that express the CD47 receptor SIRP $\alpha$. Therefore, the increased CD47 expression on tumor cells and infiltrated macrophages identified in the present study may further enhance the inhibitory 'do not eat me' signal, which contributes to the tumor cell evasion of immune surveillance.

In tumor tissue, macrophages may be characterized as M1 or M2. M1 macrophages exhibit anti-tumor activity and M2 macrophages exhibit pro-tumor activity (36). It has been demonstrated that blocking CD47-SIRP $\alpha$ signaling with anti-CD47 antibodies enhances phagocytic activity 
from M1 and M2 macrophages and promotes tumor regression (37). Furthermore, blocking CD47-SIRP $\alpha$ signaling enhances the macrophage phagocytosis of various tumor cells in vitro $(18,22,38)$. In the present study, it was demonstrated that human M2 macrophages phagocytized CD47-high ESCC cells in a dose-dependent manner following the addition of anti-CD47 antibodies to the cell culture. To the best of our knowledge, the present study is the first to demonstrate macrophage phagocytic activity against EC cells in vitro. These results support the use of CD47 as a target for the treatment of ESCC.

In conclusion, the present study demonstrates high CD47 expression and macrophage infiltration in patients with ESCC, which allows tumor cells to hijack CD47-SIRP $\alpha$ inhibitory signaling and avoid attack by immune cells. Anti-CD47 antibodies may enhance macrophage phagocytic activity against ESCC cells in vitro. The present study provides a rationale for the potential use of anti-CD47 antibodies in novel therapeutic strategies to treat ESCC.

\section{Acknowledgements}

The present study was supported by the National Natural Science Foundation of China (grant no. 81670311).

\section{References}

1. Enzinger PC and Mayer RJ: Esophageal cancer. N Engl J Med 349: 2241-2252, 2003

2. Zeng H, Zheng R, Zhang S, Zuo T, Xia C, Zou X and Chen W: Esophageal cancer statistics in China, 2011: Estimates based on 177 cancer registries. Thorac Cancer 7: 232-237, 2016.

3. Napier KJ, Scheerer M and Misra S: Esophageal cancer: A review of epidemiology, pathogenesis, staging workup and treatment modalities. World J Gastrointest Oncol 6: 112-120, 2014.

4. Lagergren $\mathrm{J}$ and Lagergren P: Recent developments in esophageal adenocarcinoma. CA Cancer J Clin 63: 232-248, 2013.

5. Sohda M and Kuwano H: Current status and future prospects for esophageal cancer treatment. Ann Thorac Cardiovasc Surg 23: $1-11,2017$.

6. Gebski V, Burmeister B, Smithers BM, Foo K, Zalcberg J and Simes J; Australasian Gastro-Intestinal Trials Group: Survival benefits from neoadjuvant chemoradiotherapy or chemotherapy in oesophageal carcinoma: A meta-analysis. Lancet Oncol 8: 226-234, 2007.

7. Tepper J, Krasna MJ, Niedzwiecki D, Hollis D, Reed CE, Goldberg R, Kiel K, Willett C, Sugarbaker D and Mayer R: Phase Iii trial of trimodality therapy with cisplatin, fluorouracil, radiotherapy, and surgery compared with surgery alone for esophageal cancer: CALGB 9781. J Clin Oncol 26: 1086-1092, 2008.

8. Kamta J, Chaar M, Ande A, Altomare DA and Ait-Oudhia S: Advancing cancer therapy with present and emerging immuno-oncology approaches. Front Oncol 7: 64, 2017.

9. Doi T, Piha-Paul SA, Jalal SI, Mai-Dang H, Yuan S, Koshiji M, Csiki I and Bennouna J: Pembrolizumab (Mk-3475) for patients (Pts) with advanced esophageal carcinoma: Preliminary results from keynote-028. J Clin Oncol: 33, 2015.

10. Kudo T, Hamamoto Y, Kato K, Ura T, Kojima T, Tsushima T, Hironaka S, Hara H, Satoh T, Iwasa S, et al: Nivolumab treatment for oesophageal squamous-cell carcinoma: An open-label, multicentre, phase 2 trial. Lancet Oncol 18: 631-639, 2017.

11. Gao J, Shi LZ, Zhao H, Chen J, Xiong L, He Q, Chen T, Roszik J, Bernatchez C, Woodman SE, et al: Loss of IFN- $\gamma$ pathway genes in tumor cells as a mechanism of resistance to anti-CTLA-4 therapy. Cell 167: 397-404.e9, 2016.

12. De Henau O, Rausch M, Winkler D, Campesato LF, Liu C Cymerman DH, Budhu S, Ghosh A, Pink M, Tchaicha J, et al: Overcoming resistance to checkpoint blockade therapy by targeting PI3K $\gamma$ in myeloid cells. Nature 539: 443-447, 2016.
13. Zaretsky JM, Garcia-Diaz A, Shin DS, Escuin-Ordinas H, Hugo W, Hu-Lieskovan S, Torrejon DY, Abril-Rodriguez G, Sandoval S, Barthly L, et al: Mutations associated with acquired resistance to PD-1 blockade in melanoma. N Engl J Med 375: 819-829, 2016.

14. Barclay AN and Van den Berg TK: The interaction between signal regulatory protein alpha (SIRP $\alpha)$ and Cd47: Structure, function, and therapeutic target. Annu Rev Immunol 32: 25-50, 2014.

15. Matozaki T, Murata Y, Okazawa $\mathrm{H}$ and Ohnishi $\mathrm{H}$ : Functions and molecular mechanisms of the CD47-SIRP $\alpha$ signalling pathway. Trends Cell Biol 19: 72-80, 2009.

16. Baccelli I, Stenzinger A, Vogel V, Pfitzner BM, Klein C, Wallwiener M, Scharpff M, Saini M, Holland-Letz T, Sinn HP, et al: Co-expression of MET and CD47 is a novel prognosticator for survival of luminal breast cancer patients. Oncotarget 5: 8147-8160, 2014.

17. Chan KS, Espinosa I, Chao M, Wong D, Ailles L, Diehn M, Gill H, Presti J Jr, Chang HY, van de Rijn M, et al: Identification, molecular characterization, clinical prognosis, and therapeutic targeting of human bladder tumor-initiating cells. Proc Natl Acad Sci USA 106: 14016-14021, 2009.

18. Tseng D, Volkmer JP, Willingham SB, Contreras-Trujillo H, Fathman JW, Fernhoff NB, Seita J, Inlay MA, Weiskopf K, Miyanishi M and Weissman IL: Anti-CD47 antibody-mediated phagocytosis of cancer by macrophages primes an effective antitumor T-cell response. Proc Natl Acad Sci USA 110: 11103-11108, 2013.

19. Zhao XW, van Beek EM, Schornagel K, Van der Maaden H, Van Houdt M, Otten MA, Finetti P, Van Egmond M, Matozaki T, Kraal G, et al: CD47-signal regulatory protein- $\alpha$ (SIRP $\alpha)$ interactions form a barrier for antibody-mediated tumor cell destruction. Proc Natl Acad Sci USA 108: 18342-18347, 2011.

20. Willingham SB, Volkmer JP, Gentles AJ, Sahoo D, Dalerba P, Mitra SS, Wang J, Contreras-Trujillo H, Martin R, Cohen JD, et al: The CD47-signal regulatory protein $\alpha(\operatorname{SIRP} \alpha)$ interaction is a therapeutic target for human solid tumors. Proc Natl Acad Sci USA 109: 6662-6667, 2012.

21. Liu X, Pu Y, Cron K, Deng L, Kline J, Frazier WA, Xu H, Peng H, Fu YX and Xu MM: CD47 blockade triggers T cell-mediated destruction of immunogenic tumors. Nat Med 21: 1209-1215, 2015.

22. Chao MP, Alizadeh AA, Tang C, Myklebust JH, Varghese B, Gill S, Jan M, Cha AC, Chan CK, Tan BT, et al: Anti-CD47 antibody synergizes with rituximab to promote phagocytosis and eradicate non-Hodgkin lymphoma. Cell 142: 699-713, 2010.

23. Majeti R, Chao MP, Alizadeh AA, Pang WW, Jaiswal S, Gibbs KD Jr, van Rooijen N and Weissman IL: CD47 is an adverse prognostic factor and therapeutic antibody target on human acute myeloid leukemia stem cells. Cell 138: 286-299, 2009.

24. Chao MP, Majeti R and Weissman IL: Programmed cell removal: A new obstacle in the road to developing cancer. Nat Rev Cancer 12: 58-67, 2011.

25. Allum WH, Bonavina L, Cassivi SD, Cuesta MA, Dong ZM, Felix VN, Figueredo E, Gatenby PA, Haverkamp L, Ibraev MA, et al: Surgical treatments for esophageal cancers. Ann N Y Acad Sci 1325: 242-268, 2014

26. Livak KJ and Schmittgen TD: Analysis of relative gene expression data using real-time quantitative PCR and the 2(-Delta Delta C(T)) method. Methods 25: 402-408, 2001.

27. Chistiakov DA, Killingsworth MC, Myasoedova VA, Orekhov AN and Bobryshev YV: CD68/macrosialin: Not just a histochemical marker. Lab Invest 97: 4-13, 2017.

28. Chao MP, Weissman IL and Majeti R: The CD47-SIRPa pathway in cancer immune evasion and potential therapeutic implications. Curr Opin Immunol 24: 225-232, 2012.

29. Parkin DM, Bray F, Ferlay J and Pisani P: Global cancer statistics, 2002. CA Cancer J Clin 55: 74-108, 2005.

30. Oldenborg PA, Zheleznyak A, Fang YF, Lagenaur CF, Gresham HD and Lindberg FP: Role of Cd47 as a marker of self on red blood cells. Science 288: 2051-2054, 2000.

31. Barclay AN: Signal regulatory protein alpha (SIRPalpha)/Cd47 interaction and function. Curr Opin Immunol 21: 47-52, 2009.

32. Liu X, Kwon H, Li Z and Fu YX: Is Cd47 an innate immune checkpoint for tumor evasion? J Hematol Oncol 10: 12, 2017.

33. Tao H, Qian P, Wang F, Yu H and Guo Y: Targeting CD47 enhances the efficacy of anti-PD-1 and CTLA-4 in esophageal squamous cell cancer preclinical model. Oncol Res: Mar 23, 2017. 
34. Suzuki S, Yokobori T, Tanaka N, Sakai M, Sano A, Inose T, Sohda M, Nakajima M, Miyazaki T, Kato H, et al: CD47 expression regulated by the miR-133a tumor suppressor is a novel prognostic marker in esophageal squamous cell carcinoma. Oncol Rep 28: 465-472, 2012.

35. Yang C, Gao S, Zhang H, Xu L, Liu J, Wang M and Zhang S: CD47 is a potential target for the treatment of laryngeal squamous cell carcinoma. Cell Physiol Biochem 40: 126-136, 2016.

36. Yuan A, Hsiao YJ, Chen HY, Chen HW, Ho CC, Chen YY, Liu YC, Hong TH, Yu SL, Chen JJ, et al: Opposite effects of M1 and M2 macrophage subtypes on lung cancer progression. Sci Rep 5: 14273, 2015.
37. Zhang M, Hutter G, Kahn SA, Azad TD, Gholamin S, Xu CY Liu J, Achrol AS, Richard C, Sommerkamp P, et al: Anti-CD47 treatment stimulates phagocytosis of glioblastoma by M1 and M2 polarized macrophages and promotes M1 polarized macrophages in vivo. PLoS One 11: e0153550, 2016.

38. Weiskopf K, Jahchan NS, Schnorr PJ, Cristea S, Ring AM, Maute RL, Volkmer AK, Volkmer JP, Liu J, Lim JS, et al: CD47-blocking immunotherapies stimulate macrophage-mediated destruction of small-cell lung cancer. J Clin Invest 126: 2610-2620, 2016. 